\title{
Euglycemic Diabetic Ketoacidosis and Sodium- Glucose Cotransporter-2 Inhibitors: A Focused Review of Pathophysiology, Risk Factors, and Triggers
}

Manoj R. Somagutta ${ }^{1,2}$, Kuchalambal Agadi ${ }^{3}$, Namrata Hange ${ }^{4}$, Molly S. Jain ${ }^{5}$, Erkan Batti ${ }^{6}$, Bernard O. Emuze $^{7}$, Elizabeth O. Amos-Arowoshegbe ${ }^{8}$, Sorin Popescu ${ }^{5}$, Saad Hanan ${ }^{5}$, Varadha Retna Kumar ${ }^{9}$, Kezia Pormento ${ }^{10}$

1. Department of Medicine, California Institute of Behavioral Neurosciences \& Psychology, Fairfield, USA 2. Department of Medicine, Avalon University School of Medicine, Willemstad, CUW 3. Clinical Research, Larkin Health System, Chicago, USA 4. Public Health, Woodlands Health Campus, Singapore, SGP 5. Department of Medicine, Saint James School of Medicine, Park Ridge, USA 6. Department of Medicine, Washington University Health and Science, San Pedro, BLZ 7. Emergency Medicine, Saint James School of Medicine, Fort Worth, USA 8. Department of Medicine, Windsor University School of Medicine, Basseterre, KNA 9. Department of Nephrology, Lourdes Hospital, Kochi, IND 10. Department of Medicine, Ateneo de Manila School of Medicine and Public Health, Quezon City, PHL

Corresponding author: Manoj R. Somagutta, manojleo.go@gmail.com

\section{Abstract}

Diabetic ketoacidosis (DKA) is an acute and significant life-threatening complication of diabetes. The association of sodium-glucose cotransporter-2 inhibitors (SGLT2i) with euglycemic diabetic ketoacidosis (EDKA) has been well reported. This literature review was conducted to understand the mechanism of EDKA and identify the potential risk factors and precipitants for patients taking SGLT2i. After reviewing the published literature between 2010 and 2020, 32 articles are included in the final review. The underlying mechanism is mainly enhanced lipolysis and ketone body reabsorption. SGLT2i also stimulates pancreatic alpha cells and inhibits beta cells, causing an imbalance in glucagon/insulin levels, further contributing to lipolysis and ketogenesis. Most patients were diagnosed with blood glucose less than $200 \mathrm{mg} / \mathrm{dL}$, blood pH $<7.3$, increased anion gap, increased blood, or urine ketones. Perioperative fasting, pancreatic etiology, low carbohydrate or ketogenic diet, obesity, and malignancy are identified precipitants in this review. As normoglycemia can conceal the underlying acidosis, physicians should be cognizant of the EDKA diagnosis and initiate prompt treatment. Patient education on risk factors and triggers is recommended to avoid future events.

Received 01/29/2021 Review began 02/25/2021 Review ended 02/26/2021 Published 03/03/2021

\section{() Copyright 2021}

Somagutta et al. This is an open access article distributed under the terms of the Creative Commons Attribution License CC-BY 4.0., which permits unrestricted use, distribution, and reproduction in any medium, provided the original author and source are credited.
Categories: Endocrinology/Diabetes/Metabolism, Internal Medicine, Nephrology Keywords: euglycemic diabetic ketoacidosis, edka, canagliflozin, empagliflozin, diabetes, sodium, risk factors , diabetic ketoacidosis, sodium-glucose cotransporter 2 inhibitor

\section{Introduction And Background}

Diabetic ketoacidosis (DKA) is a common, life-threatening complication seen in patients with type 1 and type 2 diabetes mellitus (T2DM) [1]. The following three main findings mark the diagnosis: high anion gap metabolic acidosis ( $\mathrm{pH}<7.3$ and serum bicarbonate $<15 \mathrm{mEq} / \mathrm{dL}$ ), ketone bodies in the blood and/or urine, and high blood sugar levels ranging $250-600 \mathrm{mg} / \mathrm{dL}$ [2]. In a subgroup of patients with diabetes, ketonemia and metabolic acidosis occur without a concurrent rise in blood sugar levels ( $<200 \mathrm{mg} / \mathrm{dL})$, which poses a diagnostic challenge for euglycemic diabetic ketoacidosis (EDKA). Munro et al. first described this occurrence in 1973 in a study involving 211 patients with DKA, of which 37 exhibited a normal glycemic status with ketoacidosis. With the emergence of oral hypoglycemic agents like sodium-glucose cotransporter inhibitors (SGLT2i), EDKA has been reportedly rising [3].

The increased prevalence of EDKA is seen with SGLT2i, which are federally approved medications to treat T2DM [4]. The exceptionally high incidence of T2DM across different ethnic groups has made it extremely important for physicians to understand the complications of the drugs used to treat this disease. However, there is mounting evidence of additional causes of EDKA. The common hypothesis in all factors triggering euglycemia is a state of significant carbohydrate deficit that leads to hypoinsulinemia $[5,6]$. Insulinopenia, along with an excess of counterregulatory hormone production, results in an increased glucagon insulin ratio, which accelerates lipolysis and ketonemia [6,7]. The counterregulatory hormone production is especially significant in stress on the body, such as surgery or sepsis $[2,7]$.

Limited studies have discussed EDKA; however, its increasing incidence warrants a more thorough investigation to prompt physicians worldwide to consider ketosis in a diabetic patient despite their normal serum glucose levels. In a meta-analysis published by Burke et al. in 2017, the leading risk factors that predispose an individual on SGLT2i to DKA include medication noncompliance, infection, major surgeries, 
and underlying autoimmune diabetes in patients previously diagnosed with T2DM [7]. Other precipitating factors for euglycemic EDKA are similar to hyperglycemic DKA and include starvation, infarction, pregnancy, ketogenic diet, low carbohydrate diet, dehydration, recent reduction in insulin dose, and extreme physical activity, among others [2-10]. This review summarizes the various risk factors, triggering agents, pathophysiology, and therapeutic methods involved.

\section{Review}

\section{Methods and results}

A specific literature search was performed to identify articles for EDKA risk factors and precipitants for patients on SGLT2i. We searched numerous databases such as PubMed, Google Scholar, Web of Science, and Scopus to search for published literature on this topic published between 2010 and 2020. A detailed literature search of the articles referenced in the identified publications was also performed. The keywords used included but are not limited to "euglycemic diabetic ketoacidosis," "Sodium-glucose cotransporter inhibitors," "EDKA risk factors," "EDKA in dapagliflozin," "EDKA and canagliflozin," "EDKA and empagliflozin," "EDKA and SGLT2i." The inclusion criteria included case reports published between 2010 and 2020, as well as articles available in the English language. The exclusion criteria consisted of duplicate articles or abstracts only, animal studies, studies published before 2010, and articles published in languages other than English. The initial screening of abstracts yielded 411 articles. We carefully reviewed these 411 abstracts and removed duplicates, those that did not meet our inclusion criteria, and those for which full articles were not available for free. Upon screening, we finalized 33 articles to be included in this review. The PRISMA flowchart represents the article screening process to the final included articles (Figure 1).

\section{PRISMA Flow Diagram}

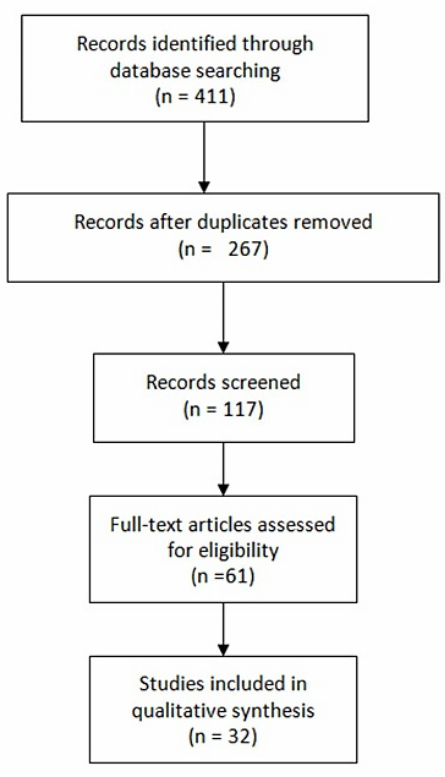

FIGURE 1: Flow chart explaining the process of the literature review.

\section{Discussion}

Sodium-Glucose Cotransporter 2

Sodium-glucose cotransporter (SGLT2) is a transmembrane protein and, as its name suggests, cotransports sodium and glucose across the cell membrane. Although there are six isoforms, two important forms are type 1 and 2, with the former located on the intestinal cells, and the latter mostly on the apical cells of the proximal convoluted tubules in the kidney and alpha cells of the pancreas $[10,11]$. These transporters are driven by the electrochemical gradient generated by the basolateral sodium/potassium-ATPase pump, and SGLT2 aids in the reabsorption of glucose from the proximal tubule segment 1 and 2 [11-13]. In 2013-2014, the Food and Drug Administration (FDA) approved the clinical use of SGLT2i such as canagliflozin, 
dapagliflozin, and empagliflozin to treat T2DM, either as monotherapy or in combination with other antidiabetic drugs. Its action mechanism leading to a decreased dose of insulin required in T1DM patients made it an off-label drug to manage T1DM [10]. Different clinical trials have well established the cardiorenal protective effect of SGLT2i [12]. For instance, the EMPA-REG OUTCOME trial was conducted to assess the effect of SGLT2i use in T2DM patients with a high cardiac risk. The researchers observed relative risk reductions in cardiovascular (CV) mortality by $38 \%$, hospitalization for heart failure by $35 \%$, and death from any cause by $32 \%$ [13]. The researchers hypothesize that: (i) in mild hyperketonemia caused by SGLT2i, betahydroxybutyrate is freely taken up by the cells as a source of energy, especially by the cardiac muscles. Use of this energy source helps the tissues work efficiently. (ii) Glucosuria and ketonuria cause a mild hemoconcentration ensuring more efficient delivery of oxygen to the tissues. Since then, the American Diabetic Association (ADA) recommends its inclusion in treating T2DM with nephropathy and/or congestive heart failure [14]. The known side effects of SGLT2i were urinary tract infection (especially with canagliflozin), osmotic diuresis leading to increased urination, thirst, dyslipidemia, and increased excretion of uric acid. Nappi et al. reported a case of EDKA in a patient taking SGLT2i (empagliflozin) along with metformin [15]. In this patient, they noticed a concurrent acute kidney injury due to the severe osmotic diuresis apart from the delayed diagnosis of EDKA. Canagliflozin was also associated with increased amputation. In the post-marketing surveillance, it was found that SGLT2i caused EDKA. In 2015, FDA reported 73 cases of EDKA with the use of SGLT2i [16,17]. Some researchers reason that because EDKA can occur even in those not taking SGLT2i, the true incidence of EDKA in those taking SGLT2i is not known.

Pathophysiology

The underlying mechanism of SGLT2i causing EDKA is multifactorial and shown in Figure 2 [16-19].

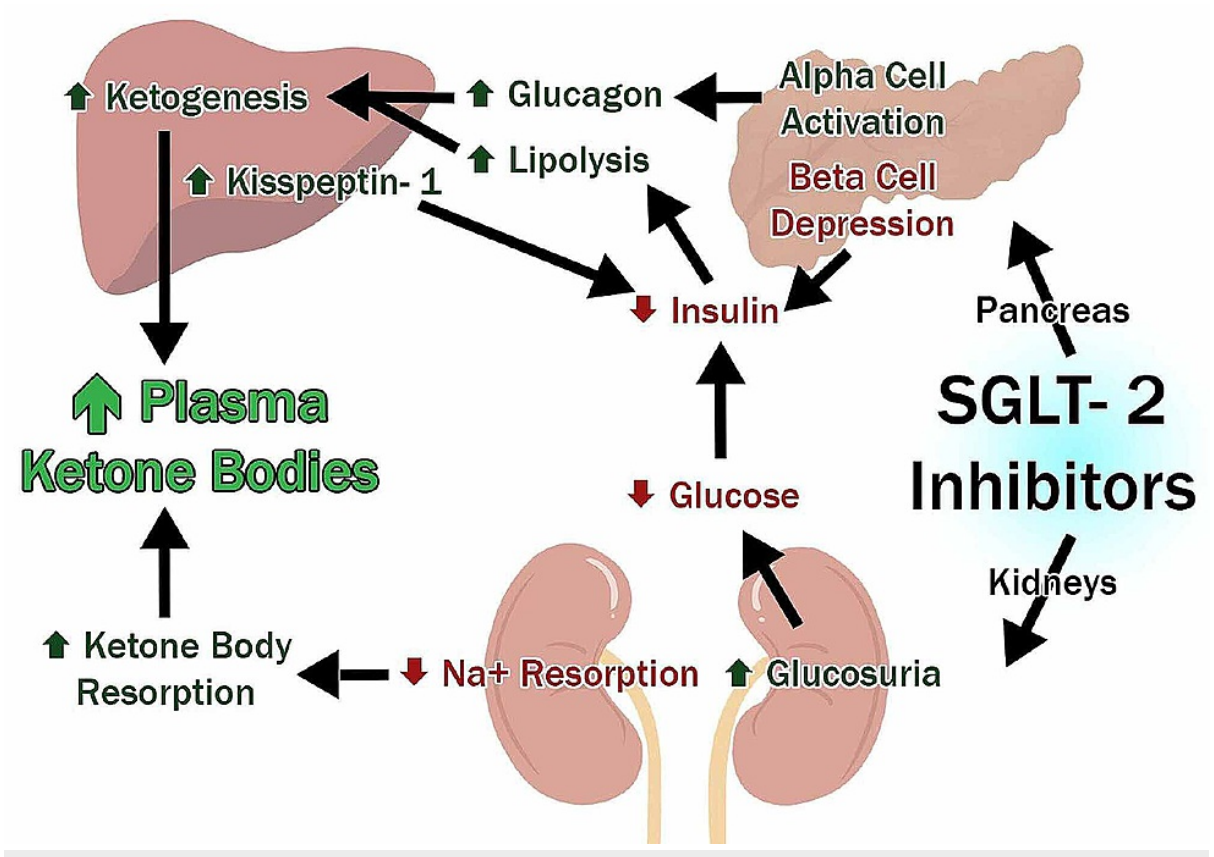

FIGURE 2: Pathophysiology and mechanism of SGLT2i causing EDKA.

SGLT2 = sodium-glucose cotransporter-2, $\mathrm{Na}^{+}$= sodium; EDKA = euglycemic diabetic ketoacidosis

SGLT2i on kidney enhance glucose excretion and causes the reabsorption of ketone bodies. In pancreas, there is contemplation that SGLT2i inhibit beta cells causing increased lipolysis, adding to the pool of ketone bodies [16-18]. They also have been found to stimulate alpha cells of the pancreas, inciting the release of glucagon and causing an imbalance in glucagon/insulin levels [18,19]. The studies so far have shown that EDKA in patients taking SGLT2i is more common among patients who have had diabetes for a long time; and there are other factors precipitating it. We reviewed the included articles for the risk factors and precipitants for EDKA in patients taking SGLT2i. We noticed 11 cases associated with pre/postoperative fasting, three associated with pancreatic etiology, five associated with low carbohydrate or keto diet, one with malignancy, and one in an obese adolescent [20-33].

The majority of the authors reported EDKA in middle-aged women with long-standing T2DM, body mass index between 35 and $40 \mathrm{~kg} / \mathrm{m}^{2}$, and who had been on multiple doses of SGLT2i for at least more than three months [34-36]. The common presenting complaints were fatigue, abdominal pain, shortness of breath, reduced food intake, nausea, and vomiting. On examination, they were tachypneic, with tachycardia, blood 
glucose less than $200 \mathrm{mg} / \mathrm{dL}$, blood pH <7.3 (7.08-7.2), increased anion gap, and increased blood ketones, such as beta-hydroxybutyrate and serum acetone. Sampani et al. reported increased ketones in the urine as well [34]. The precipitating factors, signs and symptoms, and diagnostic criteria are depicted in Figure 3 [2,7$10,20-32,34]$.

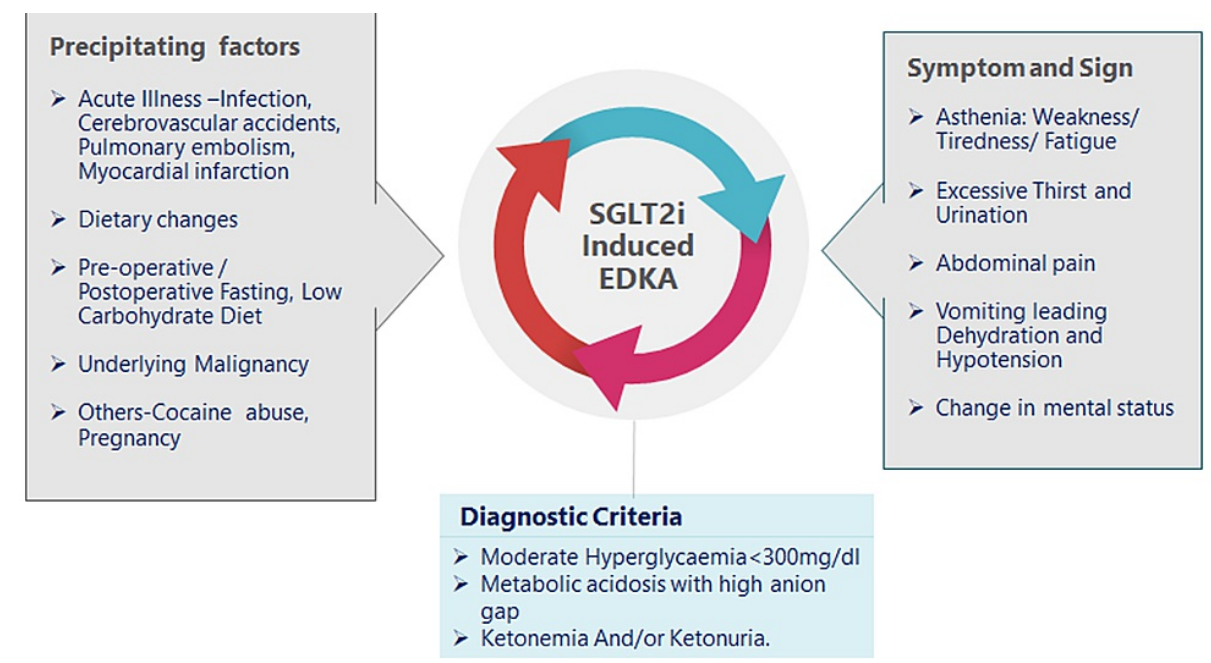

\section{FIGURE 3: Precipitating factors, symptoms, and diagnostic criteria for SGLT2i-associated EDKA.}

SGLT2i = sodium-glucose cotransporter-2 inhibitors; EDKA = euglycemic diabetic ketoacidosis

\section{Precipitating factors}

Dietary Factors

Since the 1960s, ketogenic or very low carbohydrate diets (VLCDs) have been widely recommended for weight loss. The popularity of this diet has increased with many studies proving its beneficial effects in treating patients with polydrug therapy for a seizure disorder, slowing the progression in Alzheimer's disease, improving the glucose tolerance in insulin-resistant DM, weight loss, and other neurodegenerative diseases [37]. The science behind this diet is to forcefully induce "ketosis" in individuals by restricting the carbohydrate intake to less than $50 \mathrm{~g}$ daily over several days. In some patients with diabetes, prescribing SGLT2i (which is also known to cause ketosis) or unsupervised keto diet initiation in patients who are already taking SGLT2i has placed them at risk of life-threatening EDKA [29].

SGLT2i causes the loss of glucose in the urine and increases the glucagon/insulin ratio resulting in increased gluconeogenesis, glycogenolysis, and fatty acid metabolism leading to weight loss [30]. VLCD has been proven to promote weight loss and is frequently used in the dietary management of T2DM [31]. Few authors have recorded case reports of EDKA precipitated by conditions where both SGLT2i and VLCD were instituted together $[30,38]$. Both the women adhered to a diet with less than $20 \mathrm{~g}$ of carbohydrate, with reported weight loss of more than 5 pounds in a month. They presented to the hospital with tachypnea, tachycardia, and fatigue, with blood $\mathrm{pH}$ of $<7.2$ and elevated blood ketones. They were treated successfully in the intensive care setting, with large boluses of fluids, electrolyte correction, and insulin. In both cases, physicians restarted the low carbohydrate dietary management with very close monitoring. They started carbohydrate intake of about $75 \mathrm{~g}$ a day and gradually reduced it. Shaika et al. reported a case of EDKA in a T1DM patient who had started a keto diet [31]. This case illustrates the importance of educating diabetic patients about the need to consult with their primary care provider before commencing a dietary or exercise change. The authors recommended further studies to analyze the long-term risk versus benefit of a low carbohydrate diet in diabetic patients as it causes weight loss and alters lipids by increasing low-density lipoproteins and triglycerides [31].

\section{Hypertriglyceridemia}

Two of the articles we reviewed reported cases of EDKA in the setting of SGLT2i use in patients with preexisting hypertriglyceridemia. Badwal et al. reported a case of EDKA in a 25-year-old male with a history of pancreatitis secondary to hypertriglyceridemia and diabetes managed with metformin, sitagliptin, and dapagliflozin [37]. Gajjar et al. reported the case of a 28 -year-old women on dapagliflozin and metformin for T2DM management and with triglyceride level of more than $500 \mathrm{mg} / \mathrm{dL}$ [39]. 
In both cases, patients presented with abdominal pain, nausea, and vomiting. Their initial labs showed normal glucose, increased anion gap, increased HbA1c levels, and hypertriglyceridemia of >5,000 mg/dL and $>2,000 \mathrm{mg} / \mathrm{dL}$, respectively. In both cases, the treating attendees diagnosed EDKA with elevated betahydroxybutyrate levels, and treated the patients with intensive fluid replacement, insulin infusion (discontinued all oral hypoglycemic agents), bicarbonates, and electrolytes. The former was also diagnosed with pancreatitis considering elevated lipase, while in the latter, the lipase was found to be within normal limits. Both patients reported a complete recovery and were discharged on insulin. The authors emphasized that inadequate oral intake is a confounding factor leading to ketosis and EDKA in their patients. They also highlight the importance of ordering beta-hydroxybutyrate levels to clinch the diagnosis of EDKA in suspected cases and restarting SGLT2i only after consultation with the endocrinologist.

\section{Perioperative Fasting}

The half-life of a single dose of SGLT2i varies between eight and 16 hours. Patients on a multiple-dose regimen for a prolonged time have a longer half-life [36]. In perioperative situations, patients are in a fasting state, and if the patients are on SGLT2i, they continue to lose glucose in the urine, more ketones will be reabsorbed into the tubules, and are synthesized in the liver by lipolysis. These collectively result in ketonemia and an acidotic state. These patients may also have multiple factors that might cause the acidotic state, such as starvation and possible underlying or complicating infection, and clinicians should be cautious about ruling out DKA, especially the euglycemic variety. These cases are tabulated in Table 1 .

\begin{tabular}{|c|c|c|c|c|c|}
\hline Author & Clinical profile & $\begin{array}{l}\text { Signs \& } \\
\text { symptoms }\end{array}$ & Time of event & Lab values & Treatment \\
\hline $\begin{array}{l}\text { Banakh et } \\
\text { al., } 2019 \\
\text { [20] }\end{array}$ & $\begin{array}{l}64 \text { Yrs, F with T2DM, } \\
\text { HTN, } \\
\text { hypercholesterolemia }\end{array}$ & $\begin{array}{l}\text { Dehydration, } \\
\text { tachypnoea, } \\
\text { tachycardia }\end{array}$ & $\begin{array}{l}\text { POD-4 gastric } \\
\text { sleeve surgery }\end{array}$ & $\begin{array}{l}\text { Glu }=13.5 \mathrm{mmol} / \mathrm{L}, \mathrm{ABG}: \mathrm{pH}= \\
6.93, \mathrm{HCO}_{3}=2 \mathrm{mmol} / \mathrm{L}, \mathrm{K}^{+}= \\
4.3 \mathrm{mmol} / \mathrm{L} \text {, blood ketones }= \\
\text { elevated, lactate }=1.5 \mathrm{mmol} / \mathrm{L}\end{array}$ & $\begin{array}{l}\text { ED: rapid } \\
\text { rehydration with } 3 \mathrm{~L} \\
\text { of } \mathrm{NS} \text { with } 10 \% \\
\text { dextrose and } \mathrm{NS} \\
>300 \mathrm{~mL} \text { of } 8.4 \% \\
\mathrm{NaHCO}_{3}\end{array}$ \\
\hline $\begin{array}{l}\text { Segebrecht } \\
\text { et al., } 2019 \\
\text { [21] }\end{array}$ & $\begin{array}{l}65 \text { Yrs, F with T2DM, } \\
\text { CKD stage IV }\end{array}$ & $\begin{array}{l}\text { AMS, tachypnea, } \\
\text { gastrointestinal } \\
\text { bleeding, diarrhea }\end{array}$ & $\begin{array}{l}\text { POD-11 } \\
\text { abdominal surgery } \\
\text { for incarcerated } \\
\text { hernia }\end{array}$ & $\begin{array}{l}\mathrm{BG}=118 \mathrm{mg} / \mathrm{dL}, \mathrm{pH}=7.08, \\
\mathrm{HCO}_{3}=14, \text { beta- } \\
\text { hydroxybutyrate (ketones) = } \\
8.9 \mathrm{mmol} / \mathrm{L} \mathrm{AG}=12, \text { lactate = } \\
0.4 \mathrm{mmol} / \mathrm{L}, \mathrm{BUN}=10, \mathrm{SCr}= \\
0.7\end{array}$ & $\begin{array}{l}\text { CRRT for AOCI, IV } \\
\text { fluid replacement } \\
\text { with insulin drip, } \\
50 \% \text { D }\end{array}$ \\
\hline $\begin{array}{l}\text { Segebrecht } \\
\text { et al., } 2019 \\
\text { [21] }\end{array}$ & $\begin{array}{l}75 \text { Yrs, M with T2DM, } \\
\text { AOCKD: RT done }\end{array}$ & AMS & $\begin{array}{l}\text { POD-0 exploratory } \\
\text { laparotomy with } \\
\text { right } \\
\text { hemicolectomy } \\
\text { and ileocolic } \\
\text { anastomosis }\end{array}$ & $\begin{array}{l}\mathrm{AG}=18, \mathrm{HCO}_{3}=12, \mathrm{Na}=141 \\
\text { beta-hydroxybutyrate }=5.0 \\
\mathrm{mmol} / \mathrm{L}, \text { lactate }=1.5 \mathrm{mmol} / \mathrm{L}\end{array}$ & $\begin{array}{l}\text { IV fluid, insulin, } \\
\text { electrolytes }\end{array}$ \\
\hline $\begin{array}{l}\text { Jaberi et } \\
\text { al., } 2016 \\
\text { [22] }\end{array}$ & $\begin{array}{l}47 \text { Yrs, F with T2DM, } \\
\text { Graves disease, } \\
\text { post- } \\
\text { cholecystectomy, } \\
\text { hyperlipidemia, } \\
\text { depression }\end{array}$ & $\begin{array}{l}\text { AMS nausea, } \\
\text { vomiting, } \\
\text { dehydration }\end{array}$ & $\begin{array}{l}\text { POD-2 after hip } \\
\text { replacement } \\
\text { surgery }\end{array}$ & $\begin{array}{l}\mathrm{BG}=152 \mathrm{mg} / \mathrm{dL}, \mathrm{pH}=7.18 \mathrm{~K}^{+} \\
=4.4 \mathrm{mEq} / \mathrm{L} \mathrm{AG}=17, \mathrm{HCO}_{3}= \\
9.2 \mathrm{mg} / \mathrm{dL}, \text { ketonuria }=2+, \\
\mathrm{HCO}_{3}=17, \text { lactate }=1 \mathrm{mmol} / \mathrm{L}\end{array}$ & $\begin{array}{l}\text { IV fluid, insulin, } \\
\text { electrolytes }\end{array}$ \\
\hline $\begin{array}{l}\text { Mackintosh } \\
\text { et al., } 2020 \\
\text { [23] }\end{array}$ & 68 Yrs, F with T2DM & $\begin{array}{l}\text { Increasingly } \\
\text { lethargic with } \\
\text { confusion and } \\
\text { worsening } \\
\text { expressive } \\
\text { aphasia }\end{array}$ & $\begin{array}{l}\text { POD-1 craniotomy } \\
\text { with tumor } \\
\text { excision }\end{array}$ & $\begin{array}{l}\mathrm{BG}=160 \mathrm{mmol} / \mathrm{L}, \mathrm{HCO}_{3}=9 \\
\mathrm{mmol} / \mathrm{L}, \mathrm{AG}=21, \mathrm{pH}=7.2 \\
\text { beta-hydroxybutyrate = high, } \\
\text { ketonuria ++, glucosuria ++ }\end{array}$ & $\begin{array}{l}\text { IV fluid, insulin, } \\
\text { electrolytes }\end{array}$ \\
\hline $\begin{array}{l}\text { Jemma } \\
\text { Dowset et } \\
\text { al., } 2019 \\
{[24]}\end{array}$ & $\begin{array}{l}43 \text { Yrs, F with T1DM, } \\
\text { obesity }\end{array}$ & $\begin{array}{l}\text { Dyspepsia and } \\
\text { nausea, } \\
\text { decreased oral } \\
\text { intake, vomiting }\end{array}$ & $\begin{array}{l}\text { POD-10, post- } \\
\text { sleeve } \\
\text { gastrectomy }\end{array}$ & $\begin{array}{l}\mathrm{BG}=11.1 \mathrm{mmol} / \mathrm{L}, \text { ketone }= \\
3.9, \mathrm{pH}=7.26, \mathrm{pCO}_{2}=31 \\
\mathrm{mmHg}, \mathrm{HCO}_{3}=13, \text { beta- } \\
\text { hydroxybutyrate }=7.4 \mathrm{mmol} / \mathrm{L}\end{array}$ & $\begin{array}{l}\text { IV fluid, insulin, } \\
\text { electrolytes }\end{array}$ \\
\hline $\begin{array}{l}\text { Bteich et } \\
\text { al., } 2019 \\
\text { [25] }\end{array}$ & $\begin{array}{l}58 \text { Yrs, F with HTN } \\
\text { and OSA }\end{array}$ & AMS & $\begin{array}{l}\text { POD-1, VP shunt } \\
\text { with malfunction }\end{array}$ & $\begin{array}{l}\mathrm{BG}=150, \mathrm{pH}=7.20, \mathrm{AG}=>28, \\
\text { beta-hydroxybutyrate }=10.09 \text {, } \\
\text { lactic acid }=1.1 \mathrm{mmol} / \mathrm{L}\end{array}$ & $\begin{array}{l}\text { IV fluid, insulin, } \\
\text { electrolytes }\end{array}$ \\
\hline
\end{tabular}




\section{Cureus}

\begin{tabular}{|c|c|c|c|c|c|}
\hline $\begin{array}{l}\text { Pace et al., } \\
2018 \text { [26] }\end{array}$ & $\begin{array}{l}66 \text { Yrs, F with T2DM, } \\
\text { pancreatic } \\
\text { adenocarcinoma, } \\
\text { ovarian mass }\end{array}$ & Polyuria & $\begin{array}{l}\text { POD-0, distal } \\
\text { pancreatectomy } \\
\text { with en bloc } \\
\text { splenectomy }\end{array}$ & $\begin{array}{l}\mathrm{BG}=\mathrm{WNL} \mathrm{HCO}_{3}=\text { low, } \mathrm{AG}= \\
\text { high, beta-hydroxybutyrate = } \\
48.1 \mathrm{mg} / \mathrm{dL}, \text { Ketonuria = +++ }\end{array}$ & $\begin{array}{l}\text { IV fluid, insulin, } \\
\text { electrolytes }\end{array}$ \\
\hline $\begin{array}{l}\text { Pace et al., } \\
2018 \text { [26] }\end{array}$ & $\begin{array}{l}75 \text { Yrs, M with T2DM, } \\
\text { metastatic cancer }\end{array}$ & $\begin{array}{l}\text { Intraoperative and } \\
\text { postoperative } \\
\text { polyuria urine } \\
\text { output }=100-325 \\
\mathrm{~mL} / \mathrm{h}\end{array}$ & $\begin{array}{l}\text { POD-0, pylorus- } \\
\text { preserving } \\
\text { resection } \\
\text { pancreas }\end{array}$ & $\begin{array}{l}\mathrm{HCO}_{3}=\text { low, } \mathrm{AG}=19 \mathrm{mmol} / \mathrm{L} \\
\text { beta-hydroxybutyrate }=50.8 \\
\mathrm{mg} / \mathrm{dL} \text {, lactic acidosis }= \\
\text { negative }\end{array}$ & $\begin{array}{l}\text { Fluids with insulin } \\
\text { drip was given, } \\
\text { frequent lab tests } \\
\text { were done }\end{array}$ \\
\hline $\begin{array}{l}\text { Mohammed } \\
\text { Faraz et al., } \\
2019 \text { [27] }\end{array}$ & $\begin{array}{l}44 \text { Yrs, F with T2DM, } \\
\text { dyslipidemia, obesity }\end{array}$ & $\begin{array}{l}\text { Generalized } \\
\text { weakness nausea } \\
\text { and anorexia, } \\
\text { tachypnea, } \\
\text { tachycardia, } \\
\text { dehydration }\end{array}$ & $\begin{array}{l}\text { POD-1, post C5- } \\
\text { C7 cervical } \\
\text { decompression }\end{array}$ & $\begin{array}{l}\mathrm{BG}=9.4 \mathrm{mmol} / \mathrm{L}, \mathrm{pH}=7.27, \\
\mathrm{HCO}_{3}=18.2 \mathrm{mmol} / \mathrm{L}, \mathrm{AG}= \\
33.8 \text { ketonuria }=4+, \text { glycosuria } \\
=2+, \text { lactate }=0.8 \mathrm{mmol} / \mathrm{L}\end{array}$ & $\begin{array}{l}\text { IV fluid, insulin, } \\
\text { electrolytes }\end{array}$ \\
\hline $\begin{array}{l}\text { Mohammed } \\
\text { Faraz et al., } \\
2019 \text { [27] }\end{array}$ & $\begin{array}{l}59 \text { Yrs, F with PMH, } \\
\text { T2DM, HTN, PCOS, } \\
\text { depression }\end{array}$ & $\begin{array}{l}\text { Generalized } \\
\text { weakness, } \\
\text { dyspnea, } \\
\text { tachypnea, } \\
\text { tachycardia, } \\
\text { dehydration }\end{array}$ & $\begin{array}{l}\text { POD-3, } \\
\text { laparoscopic right } \\
\text { partial } \\
\text { nephrectomy }\end{array}$ & $\begin{array}{l}\text { Glucose }=12.3 \mathrm{mmol} / \mathrm{L}, \mathrm{pH}= \\
7.23, \mathrm{HCO}_{3}=9.3 \mathrm{AG}=32.6 \\
\text { ketonuria }=3+, \text { glycosuria }= \\
2+, \text { lactate }=0.5 \mathrm{mmol} / \mathrm{L}\end{array}$ & $\begin{array}{l}\text { IV fluid, insulin, } \\
\text { electrolytes }\end{array}$ \\
\hline
\end{tabular}

\section{TABLE 1: Cases of EDKA in patients receiving SGLT2i triggered by pre/postoperative fasting.}

Yrs = years; F = female; $M$ = Male; PMH = past medical history; T2DM = type 2 diabetes mellitus; SOB = shortness of breath; HTN = hypertension; OSA: obstructive sleep apnea; AMS = altered mental status; CRRT = continuous renal replacement therapy; AOCKI IV = acute on chronic stage IV kidney injury; $\mathrm{Cx}=$ complicated; $\mathrm{POD}=$ postoperative day; $\mathrm{ABG}=$ arterial blood gas; $\mathrm{AG}=$ anion gap; $\mathrm{BG}=$ blood glucose; $\mathrm{BUN}=$ blood urea nitrogen; EDKA = euglycemic diabetic ketoacidosis

One of the advantages of SGLT2i treatment is weight loss. With rapid weight loss, increased lipolysis in the liver results in ketogenesis and precipitates starvation ketosis. In a situation that warrants surgery, the patient is placed on nil per oral, which further aggravates the condition. Banakh et al. reported how EDKA is mistaken for starvation ketosis [20]. Starvation ketoacidosis is usually associated with milder $\mathrm{pH}$ of $>7.3$, serum bicarbonate $>18$, free fatty acids in serum, and keto-anion levels lower than in EDKA. Most authors have reported altered mental status as a presenting symptom in postoperative patients who were later diagnosed as having EDKA. Pace et al. noted immediate postoperative polyuria [26]. Similar to the management of regular diabetic ketoacidosis, the euglycemic variant is an emergency that needs to be addressed in the intensive care unit with intensive fluid replacement, electrolyte correction, insulin drip, frequent blood draws, and, importantly, stopping the SGLT2i (if it was not done yet). Most authors reported that their patients recovered with the above management. Wang et al. noted that their patient scheduled for revascularization procedure for moyamoya disease suffered from an acute left cerebral infarct and succumbed to the stroke [35]. Segebrecht et al. reported that the antibiotics-induced pseudomembranous colitis precipitated the EDKA in their patient who underwent abdominal surgery [21].

We found that most patients were on SGLT2i therapy for more than six months. Handelsman et al. suggested that SGLT2i drugs be stopped for at least 24-72 hours before the surgery as both stress and surgery can aggravate the risk of ketosis [40]. However, Pace et al. suggested that because SGLT2i have long half-lives, they should be withheld for at least five days before surgery to avoid perioperative ketosis [26]. Even after prompt discontinuation of these drugs, EDKA should be highly suspected and appropriate measures should be taken if these patients present postoperatively with altered mental status, polyuria, glucosuria, tachypnea, tachycardia, or ketosis. They also note that T2DM patients are usually on a multidrug antidiabetic regimen and recommend that physicians' be vigilant about the rare but noted side effects of hypoglycemic agents, such as pancreatitis due to glucagon-like peptide-1 receptor agonist and heart failure due to di peptidase- 4 inhibitors. Bteich et al. added that, in addition to stopping the SGLT-2i preoperatively, these patients should also be started prophylactically on low doses of long-acting insulin [25]. This is because EDKA is precipitated by an imbalance between glucagon/insulin, with the added effect of increased catecholamines and cortisol levels in patients taking SGLT2i [32].

Infection

Muppidi et al. reported a young pregnant woman with T1DM presenting with urinary tract infection symptoms, causing nausea and vomiting in her third trimester of pregnancy [41]. Her blood glucose was $<200$ $\mathrm{mg} / \mathrm{dL}$ with ketosis and metabolic acidosis. They treated her aggressively and promptly with fluids, insulin, 
electrolyte replacement, urinary tract infection treatment, fetal monitoring, and emergency caesarian section. They explained that pregnant women are at an increased risk of acidosis due to factors such as decreased calorie consumption, hormonal changes in the late stages of pregnancy (such as increased estrogen, progesterone, HPL, TNF-alpha, decreased insulin), and respiratory changes in the late stages of pregnancy. Infection, sepsis, and T1DM are also independent factors known to precipitate acidosis. The presence of all factors at once precipitated the severe ketoacidosis state in this case. The usual DKA in a pregnant woman can cause many deleterious effects on maternal and fetal health, including fetal complications due to uterine hypoperfusion, fetal hypoxia, and impaired fetal brain development. The euglycemic state further increases the challenge in diagnosing the condition and treating promptly.

Malignancy

Lucero et al. report a case of EDKA in a 50-year-old woman with hypertension, T2DM, hypothyroidism, dyslipidemia, and left breast cancer, which required treatment with surgery chemoradiation [42]. The patient was treated with $10 \mathrm{mg}$ /day of dapagliflozin. Her labs were $\mathrm{pH}$ of 7.13, anionic gap 32, and blood glucose 165 $\mathrm{mg} / \mathrm{dL}$, with positive ketonemia. After the diagnosis is made, treatment with a continuous insulin infusion pump was started and the patient was discharged from the hospital after five days. Papadokostaki and Liberopoulos reported the case of a 64-year-old male with T2DM, hypertension presenting with nausea, vomiting, and abdominal pain [32]. He was started on dapagliflozin eight months before his presentation. On further assessment, he had tachycardia and tenderness in the epigastrium and left upper quadrant. In his labs, pH was 7.33, low bicarbonate, $\mathrm{K}^{+} 4.6 \mathrm{mmol} / \mathrm{L}$, increased anion gap ( $29 \mathrm{mmol} / \mathrm{L}$ ), and plasma glucose of $203 \mathrm{mg} / \mathrm{dL}$, with glucosuria and ketonuria. EDKA was diagnosed and he was managed in the intensive care unit with fluids, electrolytes, and broad-spectrum antibiotics. His condition began to improve after 48 hours. He was found to have colonic splenic flexure cancer on further investigation, for which he underwent a left hemicolectomy. Dapagliflozin was stopped, and basal-bolus insulin was prescribed. On both occasions, the authors stated that there is no clear evidence to indicate that SGLT2i use in patients with cancer increased the risk of EDKA. They recommended that further studies be conducted to elucidate if malignancy increases the risk of EDKA.

\section{Conclusions}

SGLT2i are now widely used to control hyperglycemia in diabetic patients. These medications are gaining popularity in diabetic management, mainly due to their proven CV and renal benefits in recent studies. The risk factors for EDKA in patients taking SGLT2i are diverse, and many preexisting or acute conditions can act as precipitants placing patients at risk for EDKA. Practitioners should be vigilant in diagnosing EDKA by thoughtful patient assessment for acidosis, measuring urine ketones even in normoglycemia. If EDKA is suspected, oral antidiabetic drugs, especially SGLT2i, should be discontinued and prompt treatment with intravenous fluids and insulin should be initiated in suspected patients. Patients also need to be educated about risk factors, triggers, signs, and symptoms and instructed to consult a physician before commencing any dietary changes. More research is needed to understand the mechanism of EDKA in the event of precipitants.

\section{Additional Information}

\section{Disclosures}

Conflicts of interest: In compliance with the ICMJE uniform disclosure form, all authors declare the following: Payment/services info: All authors have declared that no financial support was received from any organization for the submitted work. Financial relationships: All authors have declared that they have no financial relationships at present or within the previous three years with any organizations that might have an interest in the submitted work. Other relationships: All authors have declared that there are no other relationships or activities that could appear to have influenced the submitted work.

\section{Acknowledgements}

We would like to thank Nour Eldin Abosamak for his insights and contribution to this review.

\section{References}

1. Misra S, Oliver NS: Diabetic ketoacidosis in adults. BMJ. 2015, 351:5660. 10.1136/bmj.h5660

2. Nyenwe EA, Kitabchi AE: The evolution of diabetic ketoacidosis: an update of its etiology, pathogenesis, and management. Metabolism. 2016, 65:507-21. 10.1016/j.metabol.2015.12.007

3. Munro JF, Campbell IW, McCuish AC, Duncan LJ: Euglycaemic diabetic ketoacidosis. Br Med J. 1973, 9:57880. $10.1136 / \mathrm{bmj} .2 .5866 .578$

4. Hsia DS, Grove O, Cefalu WT: An update on SGLT2 inhibitors for the treatment of diabetes mellitus . Curr Opin Endocrinol Diabetes Obes. 2017, 24:73-9. 10.1097/MED.0000000000000311

5. Modi A, Agrawal A, Morgan F: Euglycemic diabetic ketoacidosis: a review . Curr Diabetes Rev. 2017, 13:31521. 10.2174/1573399812666160421121307

6. Rawla P, Vellipuram AR, Bandaru SS, Raj JP: Euglycemic diabetic ketoacidosis: a diagnostic and therapeutic dilemma. Endocrinol Diabetes Metab Case Rep. 2017, 2017:17-0081. 10.1530/EDM-17-0081 
7. Burke KR, Schumacher CA, Harpe SE: SGLT 2 inhibitors: a systematic review of diabetic ketoacidosis and related risk factors in the primary literature. Pharmacotherapy. 2017, 37:187-94. 10.1002/phar.1881

8. Legaspi R, Narciso P: Euglycemic diabetic ketoacidosis due to gastroparesis, a local experience . J Ark Med Soc. 2015, 112:62-3.

9. Madaan M, Aggarwal K, Sharma R, Trivedi SS: Diabetic ketoacidosis occurring with lower blood glucose levels in pregnancy: a report of two cases. J Reprod Med. 2012, 57:452-5.

10. Lin YH: Sodium-glucose cotransporter-2 inhibitors induced eu-glycemic diabetic ketoacidosis: the first report in a type 2 diabetic (T2D) Taiwanese and literature review of possible pathophysiology and contributing factors. J Formos Med Assoc. 2018, 117:849-54. 10.1016/j.jfma.2018.02.004

11. Poulsen SB, Fenton RA, Rieg T, et al.: Sodium-glucose cotransport. Curr Opin Nephrol Hypertens. 2015, 24:463-9. 10.1097/MNH.0000000000000152

12. Lee HK: Cardiorenal protective effect of sodium-glucose cotransporter 2 inhibitors and mitochondrial function. J Diabetes Investig. 2019, 10:557-9. 10.1111/jdi.12987

13. Ferrannini E, Mark M, and Mayoux E: CV protection in the EMPA-REG OUTCOME trial: a "thrifty substrate" hypothesis. Diabetes Care. 2016, 39:1108-14. 10.2337/dc16-0330

14. American Diabetes Association: Cardiovascular disease and risk management: standards of medical care in diabetes-2020. Diabetes Care. 2020, 43:111-34. 10.2337/dc20-S010

15. Nappi F, La Verde A, Carfora G, et al.: Nephrology consultation for severe SGLT2 inhibitor-induced ketoacidosis in type 2 diabetes: case report. Medicina. 2019, 55:462. 10.3390/medicina55080462

16. Candelario N, Wykretowicz J: The DKA that wasn't: a case of euglycemic diabetic ketoacidosis due to empagliflozin. Oxf Med Case Reports. 2016, 2016:144-6. 10.1093/omcr/omw061

17. Blau JE, Bauman V, Conway EM, et al.: Canagliflozin triggers the FGF23/1,25-dihydroxyvitamin D/PTH axis in healthy volunteers in a randomized crossover study. JCI Insight. 2018, 3:99123. 10.1172/jci.insight.99123

18. da Silva PN, da Conceição RA, do Couto Maia R, de Castro Barbosa ML: Sodium-glucose cotransporter 2 (SGLT-2) inhibitors: a new antidiabetic drug class. MedChemComm. 2018, 9:1273-81. 10.1039\%2Fc8md00183a

19. Pfützner A, Klonoff D, Heinemann L, Ejskjaer N, Pickup J: Euglycemic ketosis in patients with type 2 diabetes on SGLT2-inhibitor therapy-an emerging problem and solutions offered by diabetes technology. Endocrine. 2017, 56:212-6. 10.1007/s12020-017-1264-y

20. Banakh I, Kung R, Gupta S, Matthiesson K, Tiruvoipati R: Euglycemic diabetic ketoacidosis in association with dapagliflozin use after gastric sleeve surgery in a patient with type II diabetes mellitus. Clin Case Rep. 2019, 7:1087-90. 10.1002/ccr3.2147

21. Segebrecht R, Moncure M, Bennett A, Geehan D, W Van Way C 3rd, Weide L: Ketoacidosis in euglycemic patients with type 2 diabetes after abdominal surgery. JPEN J Parenter Enteral Nutr. 2019, 43:937-40. 10.1002/jpen.1594

22. Jaberi A, Seth B, Steenkamp D, Alexanian S, Borkan SC: Sodium-glucose cotransporter 2 inhibitors and euglycemic diabetic ketoacidosis: metabolic acidosis with a twist. Clin Diabetes. 2016, 34:214-6. 10.2337/cd16-0001

23. Mackintosh C, Tewari A, Siegel J, Wang RD, Freeman W: Postoperative euglycemic diabetic ketoacidosis and encephalopathy related to SGLT-2 inhibitors: a case report and discussion of diabetes treatment and "sweet pee encephalopathy" in perioperative hospital management. Neurohospitalist. 2020, 10:51-4. $10.1177 / 1941874419835035$

24. Dowsett J, Humphreys R, Krones R: Normal blood glucose and high blood ketones in a critically unwell patient with T1DM post-bariatric surgery: a case of euglycemic diabetic ketoacidosis. Obes Surg. 2019, 29:347-9. 10.1007/s11695-018-3548-6

25. Bteich F, Daher G, Kapoor A, Charbek E, Kamel G: Post-surgical euglycemic diabetic ketoacidosis in a patient on empagliflozin in the intensive care unit. Cureus. 2019, 11:4496. 10.7759/cureus.4496

26. Pace DJ, Dukleska K, Phillips S, Gleason V, Yeo CJ: Euglycemic diabetic ketoacidosis due to sodium-glucose cotransporter 2 inhibitor use in two patients undergoing pancreatectomy. J Pancreat Cancer. 2018, 4:95-9. 10.1089/pancan.2018.0016

27. Rafey MF, Butt A, Coffey B, Reddington L, Devitt A, Lappin D, Finucane FM: Prolonged acidosis is a feature of SGLT2i-induced euglycaemic diabetic ketoacidosis. Endocrinol Diabetes Metab Case Rep. 2019, 2019:190087. 10.1530/EDM-19-0087

28. Fieger EI, Fadel KM, Modarres AH, Wickham EP 3rd, Wolver SE: Successful reimplantation of a very low carbohydrate ketogenic diet after SGLT-2 inhibitor-associated euglycemic diabetic ketoacidosis. AACE Clin Case Rep. 2020, 6:330-3. 10.4158/ACCR-2020-0314

29. Islam J, Rodriguez-Martinez R, Mba MU, Ahmad A: SUN-177 house of carbs: the path to euglycemic DKA in patients with diabetes on SGLT2 inhibitors. J Endocr Soc. 2019, 3:177. 10.1210/js.2019-SUN-177

30. Earle M, Ault B, Bonney C: Euglycemic diabetic ketoacidosis in concurrent very low-carbohydrate diet and sodium-glucose transporter-2 inhibitor use: a case report. Clin Pract Cases Emerg Med. 2020, 4:185-8. 10.5811/cpcem.2020.2.45904

31. Shaikh S, Mohamed MM, Mujeeb A, Shaikh F, Harris B: Euglycemic diabetic ketoacidosis precipitated by a keto diet: importance of dietary history in diagnosis. Cureus. 2020, 12:10199. 10.7759/cureus.10199

32. Papadokostaki E, Liberopoulos E: Euglycemic diabetic ketoacidosis secondary to dapagliflozin in a patient with colon malignancy. Case Rep Endocrinol. 2019, 2019:3901741. 10.1155/2019/3901741

33. Tan H, Wang C, Yu Y: Ketosis-prone diabetes mellitus in an obese adolescent: a case report . Medicine. 2019, 98:16076. 10.1097/MD.0000000000016076

34. Sampani E, Sarafidis P, Dimitriadis C, et al.: Severe euglycemic diabetic ketoacidosis of multifactorial etiology in a type 2 diabetic patient treated with empagliflozin: case report and literature review. BMC Nephrol. 2020, 21:276. 10.1186/s12882-020-01930-6

35. Wang KM, Isom RT: SGLT2 inhibitor-induced euglycemic diabetic ketoacidosis: a case report . Kidney Med. 2020, 2:218-21. 10.1016/j.xkme.2019.12.006

36. Yehya A, Sadhu A: Sodium-glucose cotransporter 2 inhibitor-associated prolonged euglycemic diabetic ketoacidosis in type 2 diabetes: a case report and literature review. Clin Diabetes. 2020, 38:112-6. 


\section{Cureus}

10.2337/cd19-0035

37. Badwal K, Tariq T, Peirce D: Dapagliflozin-associated euglycemic diabetic ketoacidosis in a patient presenting with acute pancreatitis. Case Rep Endocrinol . 2018, 2018:6450563. 10.1155/2018/6450563

38. Hernández M, Mauricio D: Latent autoimmune diabetes in adults: a review of clinically relevant issues . Adv Exp Med Biol. 2021, 1307:29-41. 10.1007/5584_2020_533

39. Gajjar K, Luthra P: Euglycemic diabetic ketoacidosis in the setting of SGLT2 inhibitor use and hypertriglyceridemia: a case report and review of literature. Cureus. 2019, 11:4384. 10.7759/cureus.4384

40. Handelsman Y, Henry RR, Bloomgarden ZT, et al.: American Association of Clinical Endocrinologists and American College of Endocrinology position statement on the association of SGLT-2 inhibitors and diabetic ketoacidosis. Endocr Pract. 2016, 22:753-62. 10.4158/EP161292.PS

41. Muppidi V, Meegada S, Challa T, Siddamreddy S, Samal S: Euglycemic diabetic ketoacidosis in a young pregnant woman precipitated by urinary tract infection. Cureus. 2020, 12:7331. 10.7759/cureus.7331

42. Lucero P, Chapela S: Euglycemic diabetic ketoacidosis in the ICU: 3 case reports and review of literature . Case Rep Crit Care. 2018, 2018:1747850. 10.1155/2018/1747850 